\title{
The Onset of Non-Newtonian Rheology of Silicate Melts
}

\author{
A Fiber Elongation Study
}

\author{
Sharon L. Webb and Donald B. Dingwell \\ Bayerisches Geoinstitut, Universität Bayreuth, Postfach 1012 51, D-8580 Bayreuth, Federal Republic of Germany
}

Received November 2, 1989

\begin{abstract}
The viscoelastic behavior of silicate melts has been measured for a range of compositions $\left(\mathrm{NaAlSi}_{3} \mathrm{O}_{8}\right.$, $\mathrm{NaCaAlSi}_{2} \mathrm{O}_{7}, \quad \mathrm{CaMgSi}_{2} \mathrm{O}_{6}, \quad \mathrm{Li}_{2} \mathrm{Si}_{4} \mathrm{O}_{9}, \quad \mathrm{Na}_{2} \mathrm{Si}_{4} \mathrm{O}_{9}$, $\mathrm{K}_{2} \mathrm{Si}_{4} \mathrm{O}_{9}, \mathrm{Na}_{2} \mathrm{Si}_{3} \mathrm{O}_{7}, \mathrm{~K}_{2} \mathrm{Si}_{3} \mathrm{O}_{7}$ and $\mathrm{Na}_{2} \mathrm{Si}_{2} \mathrm{O}_{5}$ ) using the fiber elongation method. All compositions exhibit Newtonian behavior at low strain-rates, but non-Newtonian behavior at higher strain-rates, with strain-rate increasing faster than the applied stress. The decrease in shear viscosity observed at the high strain-rates ranges from 0.3 to $1.6 \log _{10}$ units ( $\mathrm{Pa} \mathrm{s}$ ). The relaxation strain-rates, $\dot{\varepsilon}_{\text {relax }}$, of these melts have been estimated from the low strain-rate, Newtonian, shear viscosity, using the Maxwell relationship; $\dot{\varepsilon}_{\text {relax }}=\tau^{-1}=\left(\eta_{\mathrm{s}} / G_{\infty}\right)^{-1}$. For all compositions investigated, the onset of non-Newtonian rheology is observed at strain-rates $2.5 \pm 0.5$ orders of magnitude less than the calculated relaxation strain-rate. This difference between the non-Newtonian onset and the relaxation strain-rate is larger than that predicted by the single relaxation time Maxwell model. Normalization of the experimental strain-rates to the relaxation strain-rate predicted from the Maxwell relation, eliminates the composition- and temperature-dependence of the onset of non-Newtonian behavior. The distribution of relaxation in the viscoelastic region appears to be unrelated to melt chemistry. This conclusion is consistent with the torsional, frequency domain study of Mills (1974) which illustrated a composition-invariance of the distribution of the imaginary component of the shear modulus in melts' on the $\mathrm{Na}_{2} \mathrm{O}-\mathrm{SiO}_{2}$ join. The present, time domain study of viscoelasticity contrasts with frequency domain studies in terms of the absolute strains employed. The present study employs relatively large total strains (up to 2). This compares with typical strains of $10^{-8}$ in ultrasonic (frequency domain) studies. The stresses used to achieve the strain-rates required to observe viscoelastic behavior in this study approach the tensile strength of the fibers with the result that some of our experiments were terminated by fiber breakage. Although the breakage is unrelated to the observation of non-Newtonian viscosity, their close proximity in this and earlier studies suggests that brittle failure of igneous melts, may, in
\end{abstract}

general, be preceded by a period of non-Newtonian rheology.

\section{Introduction}

Numerous investigations of the rheology of silicate melts at super-liquidus temperatures have demonstrated that the relationship between stress and strain in molten silicates is Newtonian, i.e. the strain-rate is linearly proportional to the applied stress (Bockris et al. 1955; Scarfe et al. 1983; Dingwell et al. 1985). Viscosity is a state variable and thus a strain-rate independence of viscosity implies that the thermodynamic state of the melt is independent of applied stress and the resultant strain-rate. Thus the observation of Newtonian viscosity simplifies considerably the thermodynamic description of silicate melts.

In contrast, the glass science literature contains several examples of the non-Newtonian behavior of silicate glasses (Li and Uhlmann 1970; Simmons et al. 1982; Manns and Brückner 1988; Simmons et al. 1988). Using viscoelastic models (Tool 1948; Narayanaswamy 1971; Scherer 1984), the effects of thermal and stress history on the physical properties of silicate melts have been modeled and compared with volume and shear relaxation studies (Ritland 1954; Kurkjian 1963; Mills 1974; Larsen et al. 1974; Perez et al. 1981).

The transition from viscous to viscoelastic behavior is the traditional definition of the glass transition in macroscopic, mechanical terms; with structural relaxation yielding viscoelastic behavior. Recognition of the onset of viscoelastic behavior in molten silicates is essential for the correct interpretation of experimental studies of melt properties. Similarly, modeling of the behavior of igneous magmas in stress fields requires a clear understanding of the limit of the purely viscous response.

In this study we have recorded the stress - strain behavior of a range of synthetic melt compositions just above their glass transition temperatures. The results de- 


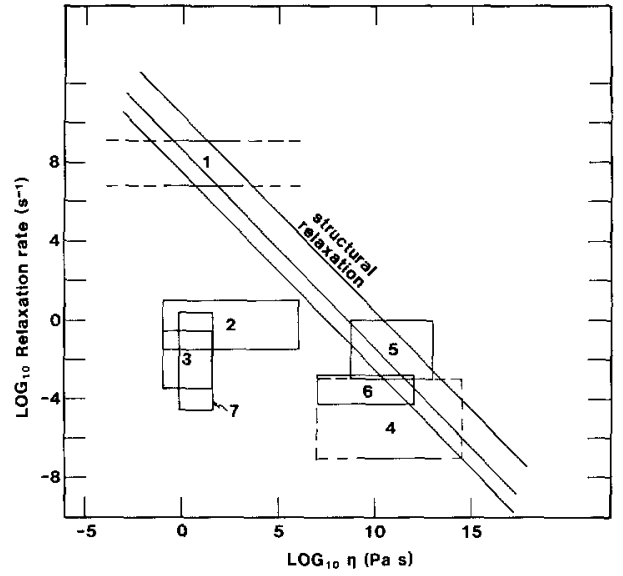

Fig. 1. The viscosity and strain-rate regions commonly attained using several different experimental techniques including ultrasonic wave propagation (1), concentric cylinder (Couette) viscometry (2), oscillation viscometry (3), fiber elongation (4), torsion pendulum (5), micropenetration (6) and falling sphere (7) viscometry. The line labelled structural relaxation is an estimate of the glass transition using Eq. 1 and a mean value of $25 \mathrm{GPa}$ for the high frequency shear modulus. Also drawn are lines at 2 and $3 \log _{10}$ units from the relaxation line (see text for discussion)

scribe the onset of measurable viscoelastic behavior in silicate melts. We used the Maxwell relationship to estimate the location of the glass transition (Dingwell and Webb 1989) and planned our experiments to cross from the viscous to the viscoelastic regime as a function of applied stress.

Figure 1 illustrates the viscosity and strain-rate ranges of several experimental sources of viscosity data. The line labelled "structural relaxation" is an estimate of the structural relaxation rate in silicate melts obtained from the Maxwell relationship;

$\dot{\varepsilon}_{\text {relax }}=\tau^{-1}=\left(\eta_{s} / G_{\infty}\right)^{-1}$

where $\dot{\varepsilon}_{\text {relax }}$ is the relaxation rate, $\tau$ is the relaxation time, $\eta_{\mathrm{s}}$ is the shear viscosity and $G_{\infty}$ is the high frequency shear modulus set to $25 \mathrm{GPa}$ (Bansal and Doremus 1986). It can be seen from Fig. 1 that ultrasonic, torsion and fiber elongation techniques can access the strainrates required, at a given viscosity, to approach the glass transition. The fiber elongation experiments are time domain studies and require relatively high strains to achieve high strain-rates. In contrast, ultrasonic and torsional studies are conducted in the frequency domain where high strain-rates are achieved with high frequency but low strains $\left(\varepsilon \cong 10^{-8}\right.$, Nye 1957). We have chosen the fiber elongation method to simulate the response of natural melts undergoing macroscopic strain during geologic processes. One consequence of the requirement of relatively large strains ( $\cong 2$ in this study) is the brittle failure of fibers at stresses near the tensile strength of the melts. This behavior was observed in the present study and gives insight into the relationship between viscoelastic behavior and brittle failure.

The results of this study are compared with the pre- diction of the Maxwell relationship. The difference between the Maxwell prediction and the experimental observation of the onset of non-Newtonian behavior is independent of composition and temperature over the range of this study. Upon normalizing strain-rate to the relaxation time of each melt composition, calculated using Eq. 1, all composition-dependence of the onset of non-Newtonian behavior is removed. This observation is a valuable simplification of the onset of non-Newtonian rheology and a useful approximation for modeling of igneous behavior.

\section{Experimental Method}

The starting glasses for the alkali silicate melts were synthesized from reagent-grade oxide and carbonate powders. $\mathrm{Li}_{2} \mathrm{CO}_{3}$, $\mathrm{Na}_{2} \mathrm{CO}_{3}, \mathrm{~K}_{2} \mathrm{CO}_{3}$ and $\mathrm{SiO}_{2}$ powders were dried at $400^{\circ} \mathrm{C}$ overnight and stored at $150^{\circ} \mathrm{C}$ until use. Twenty gram powder mixtures (decarbonated equivalent) of the alkali silicate compositions were fused in a $\mathrm{Pt}_{95} \mathrm{Au}_{5}$ crucible at $1200^{\circ} \mathrm{C}$ until bubble-free.

The $\mathrm{CaMgSi}_{2} \mathrm{O}_{6}$ glass is from the viscosity study of Dingwell (1989). The $\mathrm{NaAlSi}_{3} \mathrm{O}_{8}$ and $\mathrm{NaCaAlSi}_{2} \mathrm{O}_{7}$ glasses, donated by $\mathrm{M}$. Brearley, were synthesized at Corning Glass. As the albite was vesicular, a $100 \mathrm{~g}$ batch was melted stepwise into a $50 \mathrm{~cm}^{3} \mathrm{Pt}_{95} \mathrm{Au}_{5}$ crucible and loaded into a viscometry furnace (Dingwell 1989) and held at $1600^{\circ} \mathrm{C}$. A $\mathrm{Pt}_{80} \mathrm{Rh}_{20}$ spindle was used to stir the melt at $10 \mathrm{rpm}$ for several days until glass fibers that were optically free of bubbles could be drawn. The glass fibers were analysed for composition and homogeneity using a Cameca SX-50 microprobe. The post-experiment compositions of the fibers are presented in Table 1.

Fibers with diameters ranging from 0.1 to $0.5 \mathrm{~mm}$ were drawn from each melt. The ends of each fiber were fired to form beads of $1.5 \mathrm{~mm}$ diameter, with the final fiber being $9-20 \mathrm{~mm}$ in length. All fibers were observed by optical microscopy to be bubble and crystal free except for the diopside fibers which had partially crystallized on the support beads during flaming. The crystals appeared to be restricted to the ends of the diopside glass fibers and there is nothing in the resultant diopside data to suggest that the crystals in the support beads have influenced the melt viscosity data (see below).

The stress - strain rate behavior was determined using the fiber elongation technique. The fiber strain was measured in an argon gas flow $(5 \mathrm{cc} / \mathrm{min})$ using a vertically mounted silica glass dilatometer equipped with a Kanthal ${ }^{\circledR}$ wire-wound three-zone furnace (Model TMA 402, Netzsch Gerätebau, Selb, West Germany). A $1^{\circ} \mathrm{C}$ correction was applied to the measured temperature in order to correct for the radial temperature gradient between the type $S$ thermocouple and the melt fiber. The silica glass holder of the dilatometer supports the beaded glass fiber in a fork, with the lower bead being held in the fork of a second, movable, silica glass rod. This second rod is connected to a weight pan at the top of the dilatometer via a vanadium rod. Tensile stress is applied to the sample by loading weights on the weight pan. The elongation of the fiber is monitored by the movement of the vanadium rod through the center of a calibrated linear voltage displacement transducer.

In the present determinations of viscosity, a tensile stress is applied to a melt fiber and the viscosity is determined as the ratio of the applied stress, $\sigma$, to the observed strain-rate, $\dot{\varepsilon}$. In this geometry, the observed viscosity $\eta_{\text {elong }}$ is the elongational viscosity and is related to the shear viscosity $\eta_{\mathrm{s}}$ by;

$\eta_{\text {elong }}=\frac{\sigma}{\dot{\varepsilon}}=\frac{9 \eta_{\mathrm{v}} \eta_{\mathrm{s}}}{3 \eta_{\mathrm{v}}+\eta_{\mathrm{s}}}$

where $\eta_{v}$ is the volume viscosity (e.g. Mazurin 1986). 
Table 1. Analyses of glass compositions (wt \%)

\begin{tabular}{|c|c|c|c|c|c|c|}
\hline & $\mathrm{CaMgSi}_{2} \mathrm{O}_{6}$ & $\mathrm{NaAlSi}_{3} \mathrm{O}_{8}$ & $\mathrm{NaCaAlSi}_{2} \mathrm{O}_{7}$ & $\mathrm{Na}_{2} \mathrm{Si}_{3} \mathrm{O}_{7}$ & $\mathrm{Na}_{2} \mathrm{Si}_{4} \mathrm{O}_{9}$ & $\mathrm{Li}_{2} \mathrm{Si}_{4} \mathrm{O}_{9}$ \\
\hline $\mathrm{MgO}$ & $16.39(14)$ & - & $0.11(01)$ & - & - & - \\
\hline $\mathrm{Li}_{2} \mathrm{O}$ & - & - & - & - & - & $10.70^{\mathrm{a}}$ \\
\hline $\mathrm{K}_{2} \mathrm{O}$ & - & - & - & $0.03(02)$ & - & - \\
\hline $\mathrm{Na}_{2} \mathrm{O}$ & $0.07(02)$ & $11.29(14)$ & $11.79(10)$ & $21.63(22)$ & $20.55(18)$ & - \\
\hline $\mathrm{SiO}_{2}$ & $56.80(24)$ & $69.37(28)$ & $46.46(27)$ & $77.18(26)$ & $79.52(37)$ & $88.92(18)$ \\
\hline $\mathrm{CaO}$ & $25.85(20)$ & - & $21.42(15)$ & $0.03(01)$ & $0.02(01)$ & $0.02(01)$ \\
\hline $\mathrm{Al}_{2} \mathrm{O}_{3}$ & $0.40(02)$ & $19.93(29)$ & $19.69(25)$ & $0.36(03)$ & $0.35(02)$ & $0.36(02)$ \\
\hline Total & 99.51 & 100.59 & 99.47 & 99.23 & 100.44 & 100.00 \\
\hline
\end{tabular}

Cameca SX-50 wavelength dispersive analyses using $15 \mathrm{kV}, 15 \mathrm{nA}$ on brass, $30 \mu \mathrm{m}$ defocused beam, $20 \mathrm{sec}$ count times. Standards; diopside $(\mathrm{Mg}, \mathrm{Ca}), \mathrm{Fe}_{2} \mathrm{O}_{3}(\mathrm{Fe})$, orthoclase $(\mathrm{K}, \mathrm{Al})$, and synthetic glass DGG1 (Na, Si).

${ }^{\text {a }} \mathrm{Li}_{2} \mathrm{O}$ by difference, numbers in brackets are one standard deviation

Each fiber was initially annealed in argon at temperature with a load of $\sim 10 \mathrm{MPa}$ for a period of $10^{4} \mathrm{~s}$ (strain $\approx 5 \times 10^{-2}$ ). This equilibration time is two orders of magnitude greater than both the shear and volume relaxation times of a melt with $\eta_{\mathrm{v}}=\eta_{\mathrm{s}} \approx 10^{12}$ $\mathrm{Pa} \mathrm{s}$ and $G_{\infty}$ (shear modulus) $\approx K_{\infty}$ (bulk modulus) $\approx 25 \mathrm{GPa}$ $\left(\tau_{\mathrm{v}} \approx \tau_{\mathrm{s}} \approx 40 \mathrm{~s}\right)$. The determinations of non-Newtonian viscosity were begun with this initial stress of $10 \mathrm{MPa}\left(\dot{\varepsilon} \sim 10^{-5} ; \eta_{\text {elong }} \sim\right.$ $10^{12} \mathrm{~Pa} \mathrm{~s}$ ); the applied stress being increased in steps of $\sim 25 \%$. After the application of each additional mass, the elongation of the fiber was monitored on a $1.2 \mathrm{~s}$ time interval for $\geq 300 \mathrm{~s}$. The stress and strain-rate were recalculated at each $1.2 \mathrm{~s}$ time interval to allow for the changing dimensions of the fiber.

Viscosity was determined from a point by point calculation of the stress and strain-rate experienced by the fiber. For strainrates of the order $10^{-6} \mathrm{~s}^{-1}$, errors in calculated viscosity were approximately $0.1 \log _{10} \mathrm{~Pa} \mathrm{~s}$; with increasing strain-rate to $10^{-4}$ $\mathrm{s}^{-1}$ this error was reduced to $0.01 \log _{10}$ Pa $\mathrm{s}$. It was found that constant values of strain-rate (within the $5-25 \%$ uncertainty associated with the calculated strain-rate for strain-rates $<5 \times 10^{-5}$ $\mathrm{s}^{-1}$ ) were obtained within $100 \mathrm{~s}$ of applying the weight. For a melt with $\tau=40 \mathrm{~s}$, the calculated unrelaxed strain-rate is within $8 \%$ of the relaxed strain-rate for times greater than $100 \mathrm{~s}$, illustrating that the stress - strain rate behavior approaches equilibrium within the timescale of the measurement and that the calculated shear viscosities are within error of the relaxed shear viscosities of the melt. This analysis neglects any changes in cross-sectional area and length due to elastic deformation. For the strains $\left(>5 \times 10^{-3}\right)$ of the present measurements, the effect of elastic deformation on the calculated stress and strain-rate is negligible $(<0.02 \%)$. The $0.01 \log _{10} \mathrm{~Pa} s$ uncertainty in viscosity includes the errors in length and cross-sectional area of the fibers, the errors in strain-rate determination and a further error due to temperature fluctuations and gradients.

Although infinite shear strains are possible in a melt, volume strain must be limited in magnitude (Mazurin 1986). The volume viscosity of a melt therefore approaches an infinite value with increasing time, and $\mathrm{Eq}(2)$ becomes;

$\eta_{\text {elong }}=3 \eta_{\mathrm{s}}$

for time $\gg \tau$ (Ferry 1980; Mazurin 1986). For periods $>100 \mathrm{~s}$, the shear viscosity calculated using $\mathrm{Eq}(3)$ is at most $0.02 \log _{10}$ $\mathrm{Pa}$ s less than the relaxed shear viscosity. The linear viscoelastic theory used to derive Eqs. 2 and 3 is applicable as $\dot{\varepsilon} \tau<1(\tau \cong 40 \mathrm{~s}$; $\dot{\varepsilon}<2.5 \times 10^{-2} \mathrm{~s}^{-1}$ ) for all compositions (Christensen 1982).

In an earlier study of the viscosity of Little Glass Mountain rhyolite at $\mathrm{T}=856^{\circ} \mathrm{C}$ (Webb and Dingwell 1990) Newtonian shear viscosity was observed over a stress range of $30 \mathrm{kPa}$ to $200 \mathrm{MPa}$ and a strain-rate range of $8 \times 10^{-8}-4 \times 10^{-4} \mathrm{~s}^{-1}$. Having observed
Newtonian viscosity over this large range of stress and strain-rate, the stress employed in the present measurements was increased in order to produce strain-rates approaching the calculated relaxation strain-rate of the melts. The temperature at which each melt composition was investigated was chosen in order to set the shear viscosity to $\sim 10^{12} \mathrm{~Pa} s$ as this is the optimal Newtonian viscosity for determination of non-Newtonian behavior in the present dilatometer.

\section{Results and Discussion}

With increasing strain-rate the rheology of all melts investigated was seen to become non-Newtonian (pseudoplastic), with a decrease in shear viscosity of $0.3-1.6$ $\log _{10}$ units (Pa s) being observed. It is possible that such a decrease in viscosity could be caused by viscous heating of the melt. However, from the temperature dependence of the viscosity of rhyolite (Webb and Dingwell 1990) or the present sodium-tetrasilicate (Dingwell unpublished), it is found that a temperature increase of $>8^{\circ} \mathrm{C}$ is necessary to cause the observed decrease in viscosity. The maximum temperature increase of the fiber (above the temperature of the furnace) can be calculated assuming radiative heat transfer from the fiber;

$\dot{W}=\sigma \dot{\varepsilon} V=4 e \mathrm{~S} T^{3} A \Delta T=\dot{Q}$

(Simmons et al. 1982) where $\dot{W}$ is the rate of doing work on the fiber, $V$ is the volume of the fiber, $e$ is emissivity, $\mathrm{S}$ is the Stefan-Boltzmann constant $\left(5.67 \times 10^{-8} \mathrm{~J} \mathrm{~s}^{-1}\right.$ $\left.\mathrm{m}^{-1} \mathrm{~K}^{-4}\right), A$ is the surface area of the fiber, $\Delta T$ is the increase in fiber temperature and $\dot{Q}$ is the rate of radiative heat loss. Setting the emissivity to be $\geq 0.3$, the increase in fiber temperature which can be maintained with radiative heat loss from the fiber is $\leq 0.1^{\circ} \mathrm{C}$. The Newtonian viscosities determined are in good agreement with previous studies where data are available (e.g. $\mathrm{Na}_{2} \mathrm{Si}_{4} \mathrm{O}_{9}$, Poole 1948; diopside, Tauber and Arndt 1987).

In the case of sodium-tetrasilicate, the onset of nonNewtonian behavior was observed at 6 temperatures over a $478-505^{\circ} \mathrm{C}$ range $\left(\log _{10} \eta(\mathrm{Pa} \mathrm{s})=10.72-12.06\right)$ 
Table 2. Temperature and strain-rate dependence of the viscosity of $\mathrm{Na}_{2} \mathrm{Si}_{4} \mathrm{O}_{9}$

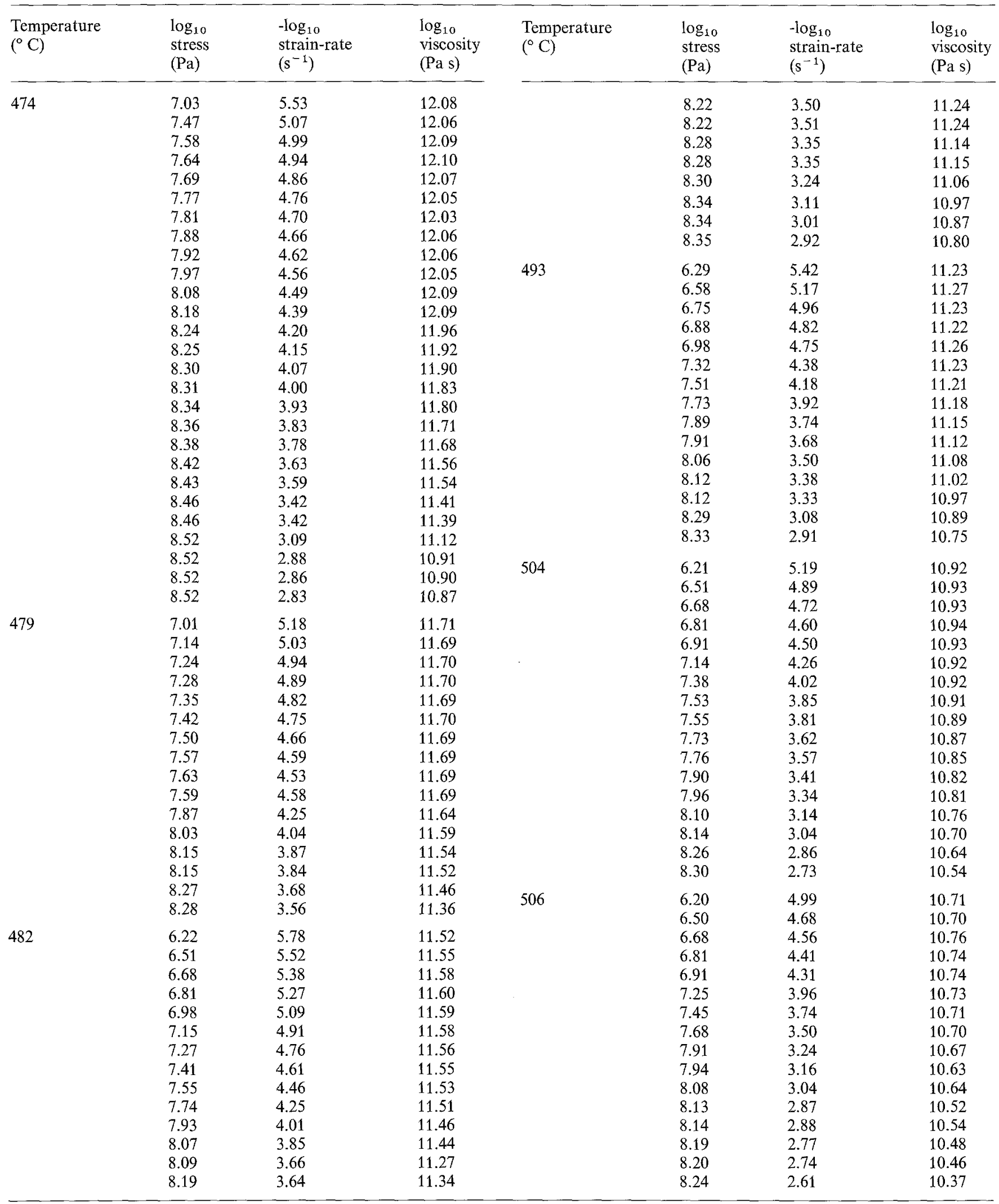




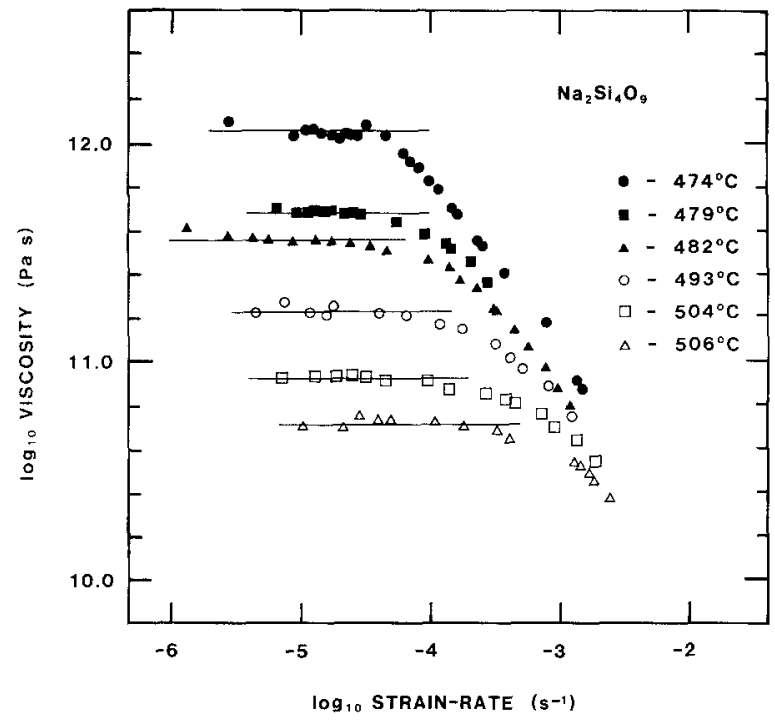

Fig. 2. The viscosity of $\mathrm{Na}_{2} \mathrm{Si}_{4} \mathrm{O}_{9}$ melt as a function of strain-rate at temperatures of $474,479,482,493,504$, and $506^{\circ} \mathrm{C}$. The onset of non-Newtonian viscosity is indicated by the departure of the data from the horizontal lines

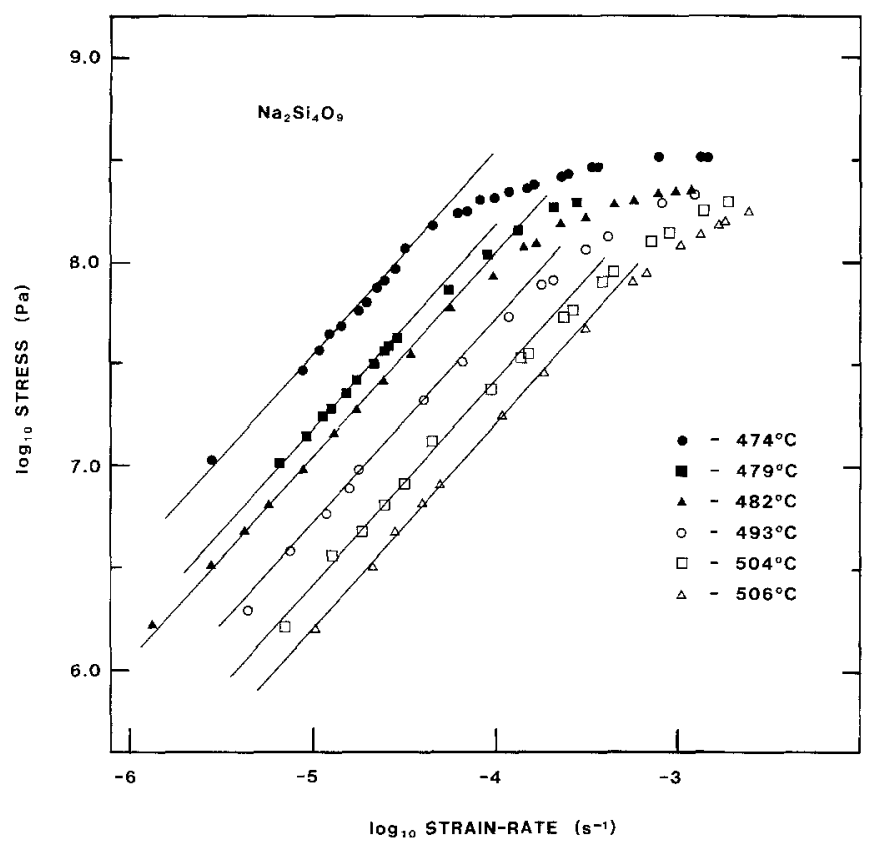

Fig. 3. The stress - strain rate relationship for $\mathrm{Na}_{2} \mathrm{Si}_{4} \mathrm{O}_{9}$ melt at temperatures of $474,479,482,493,504$, and $506^{\circ} \mathrm{C}$. Non-Newtonian behavior is indicated by departure of the data from the lines with slopes of value 1

(Table 2). The viscosity versus strain-rate behavior for this composition is plotted in Fig. 2, with the stress versus strain-rate data plotted in Fig. 3.

The rheology of $\mathrm{Li}_{2} \mathrm{Si}_{4} \mathrm{O}_{9}, \mathrm{~K}_{2} \mathrm{Si}_{4} \mathrm{O}_{9}, \mathrm{Na}_{2} \mathrm{Si}_{3} \mathrm{O}_{7}$, $\mathrm{K}_{2} \mathrm{Si}_{3} \mathrm{O}_{7}, \mathrm{Na}_{2} \mathrm{Si}_{2} \mathrm{O}_{5}, \mathrm{NaAlSi}_{3} \mathrm{O}_{8}, \mathrm{NaCaAlSi}_{2} \mathrm{O}_{7}$ and $\mathrm{CaMgSi}_{2} \mathrm{O}_{6}$ was investigated at temperatures from 849 to $446^{\circ} \mathrm{C}$ (Table 3 ). The viscosities of the alkali silicates are plotted versus strain in Fig. 4 and the stress - strain

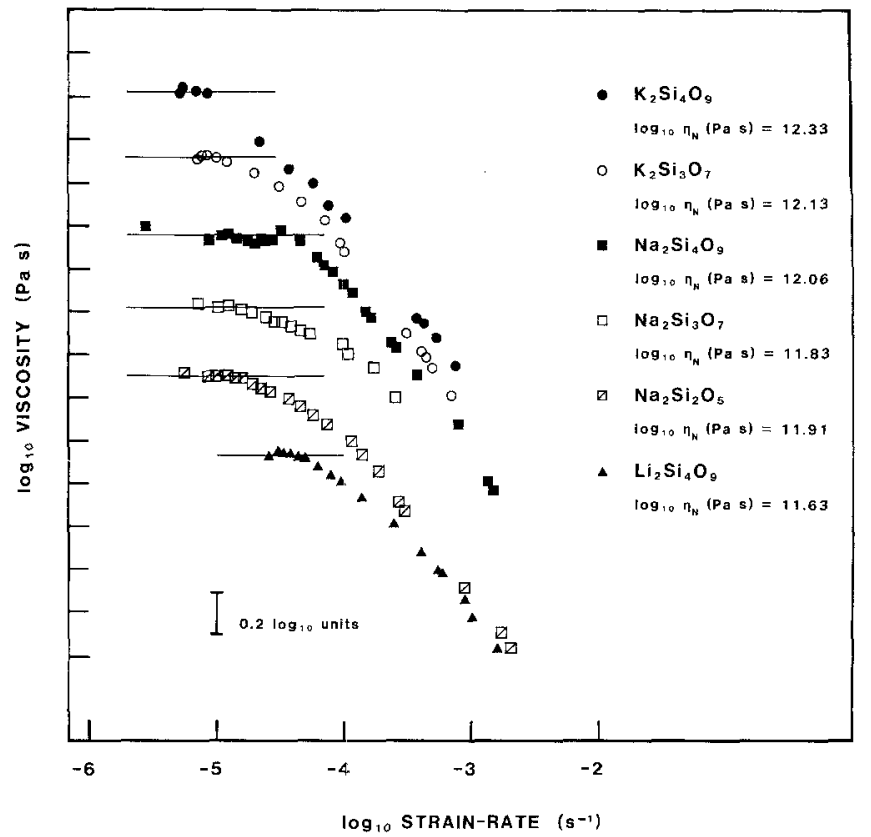

Fig. 4. The viscosities of alkali silicate melts as a function of strainrate. The onset of non-Newtonian viscosity is indicated by the departure of the data from the horizontal lines

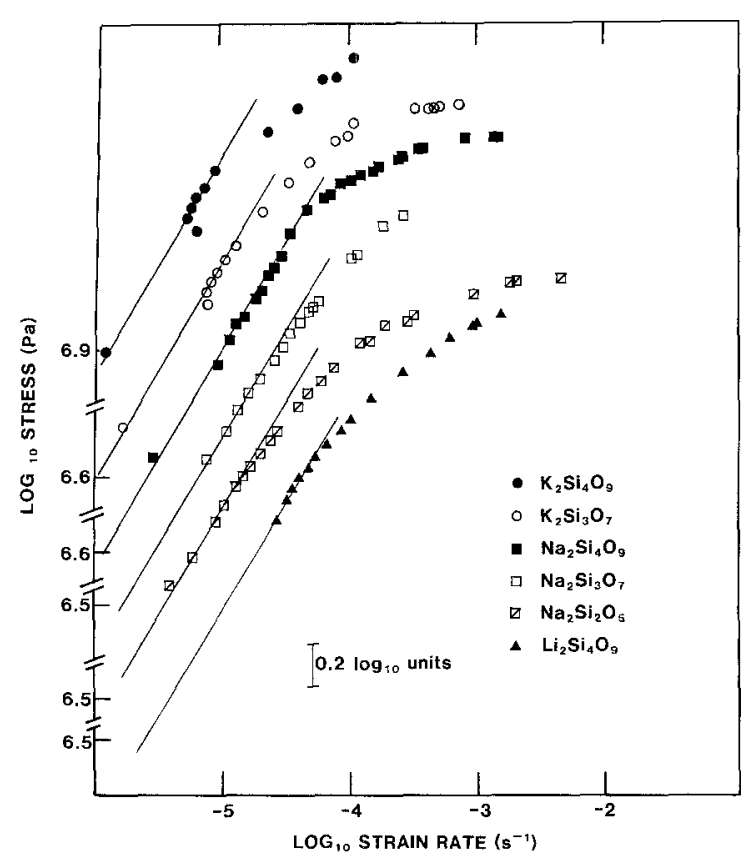

Fig. 5. The stress - strain rate relationships for alkali silicate melts. Non-Newtonian behavior is indicated by departure of the data from the lines with slopes of value 1

rate relationships are given in Fig. 5. Taking the elastic shear modulus of $\mathrm{Na}_{2} \mathrm{Si}_{4} \mathrm{O}_{9}$ to be $22 \mathrm{GPa}$ (Mills 1974), the measured shear viscosity, normalized to the Newtonian shear viscosity has been plotted in Fig. $6 \mathrm{a}$ as a function of the reduced strain-rate, $\dot{\varepsilon} / \dot{\varepsilon}_{\text {relax }}$. This reduced strain-rate is testing the assumption of thermorheological simplicity of the melt behavior. From Fig. 3 it is evident that a simple linear shift factor (i.e., the Newton- 
Table 3. Strain-rate dependence of melt viscosities

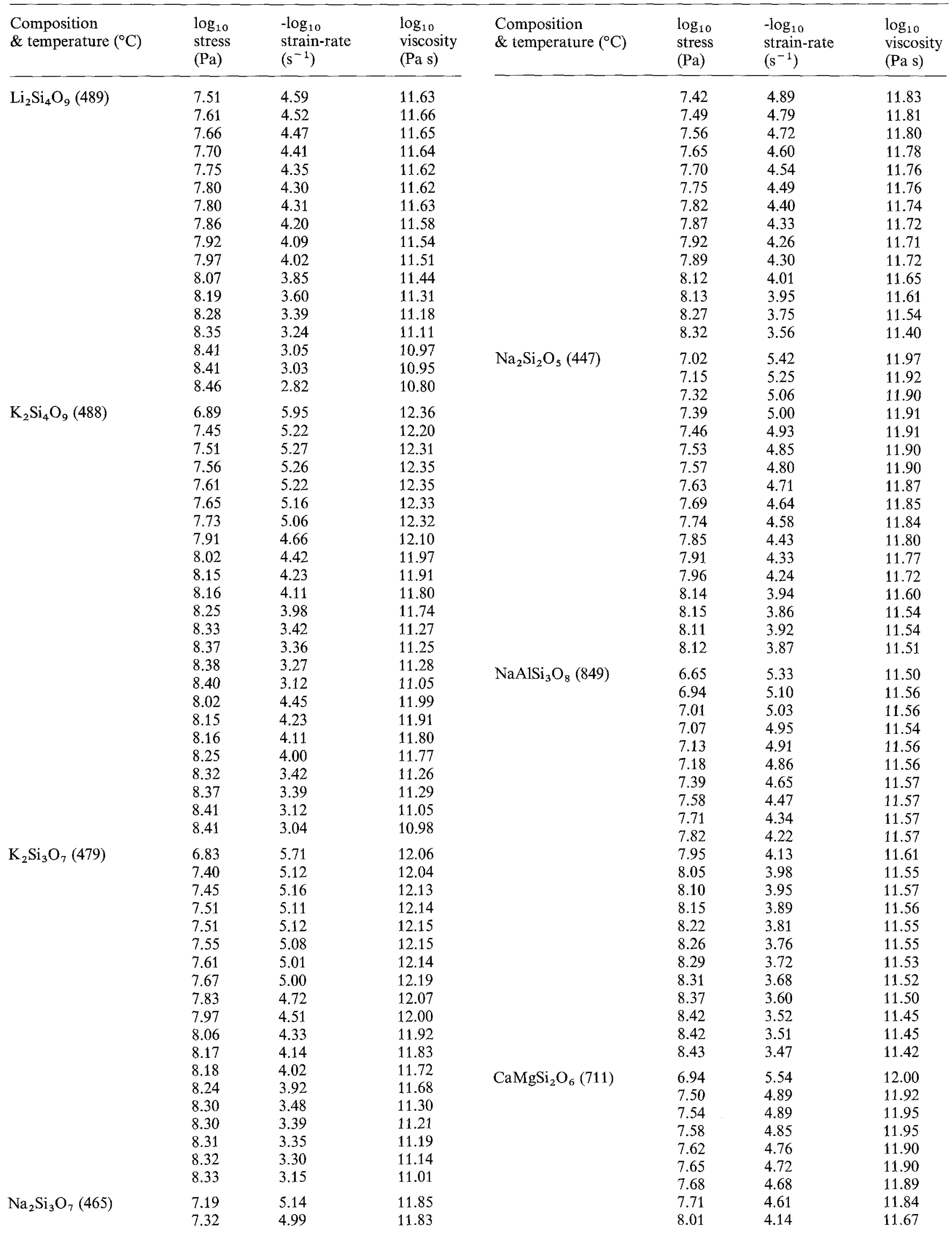


Table 3. (continued)

\begin{tabular}{|c|c|c|c|}
\hline $\begin{array}{l}\text { Composition } \\
\& \text { temperature }\left({ }^{\circ} \mathrm{C}\right)\end{array}$ & $\begin{array}{l}\log _{10} \\
\text { stress } \\
(\mathrm{Pa})\end{array}$ & $\begin{array}{l}-\log _{10} \\
\text { strain-rate } \\
\left(\mathrm{s}^{-1}\right)\end{array}$ & $\begin{array}{l}\log _{10} \\
\text { viscosity } \\
(\mathrm{Pa} \mathrm{s})\end{array}$ \\
\hline & $\begin{array}{l}8.02 \\
8.14 \\
8.16 \\
8.24 \\
8.30 \\
8.37 \\
8.42 \\
8.50\end{array}$ & $\begin{array}{l}4.07 \\
3.95 \\
3.84 \\
3.73 \\
3.43 \\
3.32 \\
2.94 \\
2.68\end{array}$ & $\begin{array}{l}11.61 \\
11.61 \\
11.52 \\
11.49 \\
11.25 \\
11.21 \\
10.88 \\
10.69\end{array}$ \\
\hline $\mathrm{NaCaAlSi}_{2} \mathrm{O}_{7}(655)$ & $\begin{array}{l}6.90 \\
7.46 \\
7.51 \\
8.54 \\
7.58 \\
7.61 \\
7.64 \\
7.67 \\
7.73 \\
7.73 \\
7.92 \\
8.12 \\
8.23 \\
8.29 \\
8.33 \\
8.39 \\
8.40 \\
8.43 \\
8.45 \\
8.46 \\
8.55 \\
8.55 \\
8.56\end{array}$ & $\begin{array}{l}5.82 \\
5.29 \\
5.30 \\
5.26 \\
5.24 \\
5.21 \\
5.19 \\
5.15 \\
5.08 \\
5.09 \\
4.85 \\
4.62 \\
4.45 \\
4.34 \\
4.26 \\
4.15 \\
4.05 \\
4.00 \\
3.87 \\
3.83 \\
3.40 \\
3.34 \\
3.32\end{array}$ & $\begin{array}{l}12.25 \\
12.28 \\
12.33 \\
12.33 \\
12.34 \\
12.34 \\
12.35 \\
12.33 \\
12.34 \\
12.34 \\
12.29 \\
12.26 \\
12.21 \\
12.16 \\
12.11 \\
12.07 \\
11.98 \\
11.95 \\
11.84 \\
11.81 \\
11.47 \\
11.41 \\
11.40\end{array}$ \\
\hline
\end{tabular}

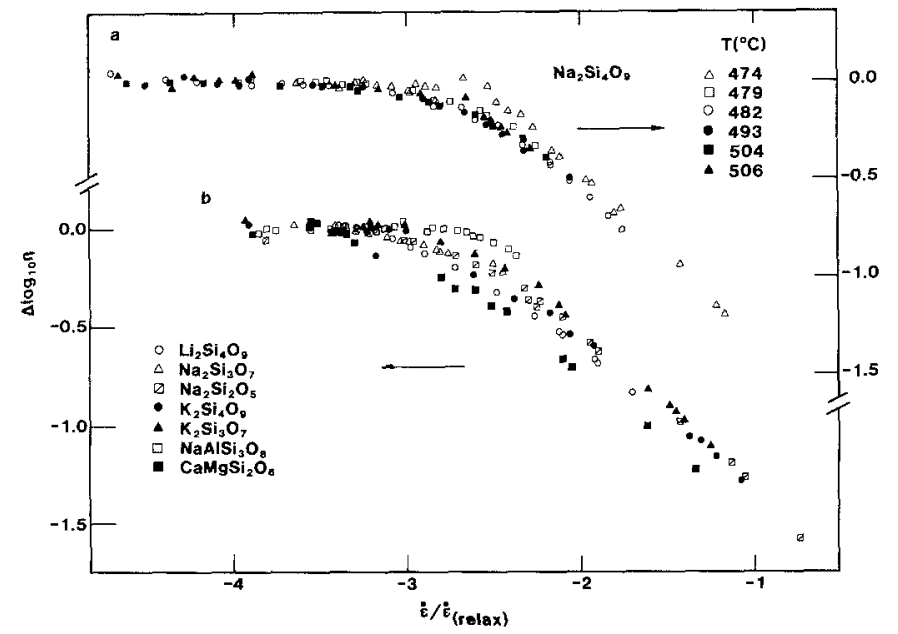

Fig. 6. 6a. A reduced plot of viscosity (relative to Newtonian) versus strain-rate (relative to relaxation strain-rate) for $\mathrm{Na}_{2} \mathrm{Si}_{4} \mathrm{O}_{9}$ at temperatures of $474,479,482,493,504$, and $506^{\circ} \mathrm{C} .6 \mathrm{~b}$. A reduced plot of viscosity versus strain-rate for the alkali silicates, albite and diopside melts. These reduced plots, based on Eq. 1 (the Maxwell equation) remove the temperature and composition dependence of the non-Newtonian viscosity of silicate melts. ian viscosity or the Maxwell relaxation time) is sufficient to remove the temperature-dependence of the onset of non-Newtonian viscosity in $\mathrm{Na}_{2} \mathrm{Si}_{4} \mathrm{O}_{9}$.

Similarly, using the Maxwell relaxation time as a normalizing factor, the compositional dependence of the onset of non-Newtonian behavior is removed $\left(G_{\infty}\right.$ data from Bansal and Doremus 1986). It can be seen from Fig. $6 \mathrm{~b}$ that there is little or no variation in reduced viscosity versus strain-rate behavior over this range of silicate compositions.

A number of studies of silicate melts in the glass transition region (e.g., torsional, Mills 1974, ultrasonics, Sato and Manghnani 1985) indicate more complex relaxation behavior than that described by a single relaxation time. Any distribution of shear relaxation times will result in a broadening of the width of the relaxation zone and the occurrence of non-relaxed behavior at lower strain-rates than predicted from the single relaxation strain-rate theory employed in the derivation of the Maxwell relationship.

Dingwell and Webb $(1989,1990)$ illustrated that relaxation in silicate melts occurs on a timescale similar to that of $\mathrm{Si}-\mathrm{O}$ bond exchange (Farnan and Stebbins 1990). Thus non-Newtonian behavior is expected as the rate of deformation of the melt approaches the rate of $\mathrm{Si}-\mathrm{O}$ bond exchange. Increasing strain-rate beyond the relaxation strain-rate of $\mathrm{Si}-\mathrm{O}$ bonds might result in another linear stress - strain rate regime with further deviations from linear stress - strain rate behavior (in effect a second glass transition) as the rate of deformation approaches the rate of relaxation of other configurational degrees of freedom in the melt (e.g. alkali exchange). These latter, "fast" relaxations in the melt structure carry strong electrical modulus signals (Provenzano et al. 1972; M. Rosenhauer 1989, personal communication) and produce internal friction peaks in silicate glasses (Day and Steinkamp 1969). Thus it is of interest to further investigate the possible overlap of the $\mathrm{Si}-\mathrm{O}$ bond relaxation and the "fast" relaxations with increasing strain-rate.

\section{Summary}

The non-Newtonian rheology of a wide range of silicate melts has been experimentally observed using the fiber elongation technique at high stresses and strain-rates. The strain-rates at which non-Newtonian behavior occurs can be estimated from the Maxwell relationship. In the present study, melts become significantly nonNewtonian at strain-rates corresponding to deformation timescales 2-3 orders of magnitude slower than the calculated relaxation time with no compositional variation being observed.

\section{References}

Bansal NP, Doremus RH (1986) Handbook of glass properties. Academic Press, New York 
Bockris JO'M, MacKenzie JD, Kitchener JA (1955) Viscous flow in silica and binary liquid silicates. Trans Faraday Soc $51: 1734$ 1748

Christensen RM (1982) Theory of viscoelasticity. Academic Press, New York

Day DE, Steinkamp WE (1969) Mechanical damping spectrum for mixed-alkali $\mathrm{R}_{2} \mathrm{O} \cdot \mathrm{Al}_{2} \mathrm{O}_{3} \cdot 6 \mathrm{SiO}_{2}$ glasses. $\mathrm{J} \mathrm{Am}$ Ceram Soc 52:571-574

Dingwell DB (1989) Effect of fluorine on the viscosity of diopside liquid. Am Mineral 74:333-338

Dingwell DB, Webb SL (1989) Structural relaxation in silicate melts and non-Newtonian melt rheology in geologic processes. Phys Chem Minerals 16:508-516

Dingwell DB, Webb SL (1990) Relaxations in silicate melts. Eur $\mathrm{J}$ Mineral (in press)

Dingwell DB, Scarfe CM, Cronin D (1985) The effect of fluorine on viscosities in the system $\mathrm{Na}_{2} \mathrm{O}-\mathrm{Al}_{2} \mathrm{O}_{3}-\mathrm{SiO}_{2}$ : Implications for phonolites, trachytes and rhyolites. Am Mineral 74:80-87

Farnan I, Stebbins JF (1990) High temperature ${ }^{29}$ Si NMR investigation of solid and molten silicates. J Am Chem Soc 112:32-39

Ferry JD (1980) Viscoelastic properties of polymers. Wiley, New York

Kurkjian CR (1963) Relaxation of torsional stress in the transformation range of a soda-lime silica glass. Phys Chem Glass $4: 128-136$

Larsen DC, Mills JJ, Sievert JL (1974) Stress relaxation behavior of soda-lime glass between the transformation and softening temperatures. J Non-Cryst Solids 14:269-279

Li JH, Uhlmann DR (1970) The flow of glass at high stress levels. J Non-Cryst Solids 33:235-248

Manns P, Brückner R (1988) Non-Newtonian flow behaviour of a soda-lime silicate glass at high deformation rates. Glastech Ber 61:46-56

Mazurin OV (1986) Glass relaxation. J Non-Cryst Solids 87:392 407

Mills JJ (1974) Low frequency storage and loss moduli of sodasilica glasses in the transformation range, J Non-Cryst Solids $14: 255-268$
Narayanaswamy OS (1971) A model of structural relaxation in glass. J Am Ceram Soc 54:491-498

Nye JF (1957) Physical properties of crystals. Oxford Press, Oxford

Perez J, Duperray B, and Lefevre D (1981) Viscoelastic behavior of an oxide glass near the glass transition temperature. J NonCryst Solids 44:113-136

Poole JP (1948) Viscosité à basse température des verres alcalinosilicatés. Verres Réfract 2:222-228

Provenzano V, Boesch LP, Volterra V, Moynihan CT, Macedo PB (1972) Electrical relaxation in $\mathrm{Na}_{2} \mathrm{O}-3 \mathrm{SiO}_{2}$ glass. J Am Ceram Soc 55:492-496

Ritland HN (1954) Density phenomena in the transformation range of a borosilicate crown glass. J Am Ceram Soc 37:370378

Sato H, Manghnani MH (1985) Ultrasonic measurements of $\mathrm{V}_{\mathrm{p}}$ and $Q_{p}$ : relaxation spectrum of complex modulus on basalt melts. Phys Earth Planet Int 41:18-33

Scarfe CM, Cronin DJ, Wenzel JT, Kaufman DA (1983) Viscositytemperature relationships at $1 \mathrm{~atm}$ in the system diopside-anorthite. Am Mineral 68:1083-1088

Scherer GW (1984) Use of the Adams-Gibbs equation in the analysis of structural relaxation. J Am Ceram Soc 67:504-511

Simmons JH, Mohr RK, Montrose CJ (1982) Non-Newtonian viscous flow in glass. J Appl Phys 53:4075-4080

Simmons JH, Ochoa R, Simmons KD, Mills JJ (1988) Non-Newtonian viscous flow in soda-lime-silica glass at forming and annealing temperatures. J Non-Cryst Solids 105:313-322

Tauber P, Arndt J (1987) The relationship between viscosity and temperature in the system anorthite-diopside. Chem Geol $62: 71-82$

Tool AQ (1948) Relation between inelastic deformability and thermal expansion of glass in its annealing range. I Am Ceram Soc 29:240-253

Webb SL, Dingwell DB (1990) Non-Newtonian rheology of igneous melts at high stresses and strain-rates: experimental results for rhyolite, andesite, basalt and nephelinite. J Geophys Res (in press) 